\title{
Rational Design of Novel Anticancer Small-Molecule RNA m6A Demethylase ALKBH5 Inhibitors
}

\section{Selberg, S}

2021-05-25

Selberg , S , Seli , N , Kankuri , E \& Karelson , M 2021, ' Rational Design of Novel Anticancer Small-Molecule RNA m6A Demethylase ALKBH5 Inhibitors ' , ACS Omega , vol. 6 , no. 20 , pp. 13310-13320 . https://doi.org/10.1021/acsomega.1c01289

http://hdl.handle.net/10138/335081

https://doi.org/10.1021/acsomega.1c01289

cc_by

publishedVersion

Downloaded from Helda, University of Helsinki institutional repository.

This is an electronic reprint of the original article.

This reprint may differ from the original in pagination and typographic detail.

Please cite the original version. 


\title{
Rational Design of Novel Anticancer Small-Molecule RNA m6A Demethylase ALKBH5 Inhibitors
}

\author{
Simona Selberg, Neinar Seli, Esko Kankuri, and Mati Karelson*
}

Cite This: ACS Omega 2021, 6, 13310-13320

Read Online

ABSTRACT: The RNA 6-N-methyladenosine (m6A) demethylase ALKBH5 has been shown to be oncogenic in several cancer types, including leukemia and glioblastoma. We present here the target-tailored development and first evaluation of the antiproliferative effects of new ALKBH5 inhibitors. Two compounds, 2-[(1-hydroxy-2-oxo-2-phenylethyl)sulfanyl]acetic acid (3) and 4-\{[(furan-2-yl)methyl $]$ amino $\}$-1,2-diazinane-3,6-dione (6), with $\mathrm{IC}_{50}$ values of 0.84 $\mu \mathrm{M}$ and $1.79 \mu \mathrm{M}$, respectively, were identified in high-throughput virtual screening of the library of 144000 preselected compounds and subsequent verification of hits in an m6A antibodybased enzyme-linked immunosorbent assay (ELISA) enzyme inhibition assay. The effect of these compounds on the proliferation of selected target cancer cell lines was then measured. In the case of three leukemia cell lines (HL-60, CCRF-CEM, and K562) the cell proliferation was suppressed at low micromolar concentrations of inhibitors, with $\mathrm{IC}_{50}$ ranging from 1.38 to 16.5 $\mu \mathrm{M}$. However, the effect was low or negligible in the case of another leukemia cell line, Jurkat, and the glioblastoma cell line A-172. These results demonstrate the potential of ALKBH5 inhibition as a cancer-cell-type-selective antiproliferative strategy.

\section{INTRODUCTION}

The interest in RNA modifications and their relevance to gene expression regulation at the RNA level has rapidly increased during the past few years. ${ }^{1,2}$ One of the most abundant modifications is N6-methyladenosine $(\mathrm{m} 6 \mathrm{~A})$ that has been detected in different types of RNA molecules. ${ }^{3,4}$ The 6aminomethylation of adenosine is dynamically regulated in mammalian cells by RNA methyltransferases or "writers", demethylases or "erasers", and $\mathrm{m} 6 \mathrm{~A}$ recognizing proteins or "readers". 5,6 Two enzymatic systems are known that transfer the methyl group from the donor substrate S-adenosylmethionine (SAM) to the 6-amino group of the adenine. First, this reaction can be catalyzed by a heterodimer complex, the core of which consists of methyltransferase-like protein 3 (METTL3) and METTL14. These can further be associated with other regulatory proteins such as Wilms tumor 1associated protein (WTAP), RBM15/RBM15B, and Virma (originally known as KIAA1429). ${ }^{7-11}$ The more recently discovered enzyme METTL16 ${ }^{12}$ targets pre-mRNAs and various noncoding RNAs $^{13}$ and participates in the regulation of SAM synthesis. ${ }^{14,15}$ The m6A modification in mRNA is specifically recognized by YT521B homology (YTH) family of proteins. ${ }^{9,16}$ Three YTHDF (YTH domain family) members, YTHDF1, YTHDF2, and YTHDF3, ${ }^{17,18}$ and two YTHDC (YTH domain-containing) proteins, YTHDC $1^{19}$ and YTHDC2, ${ }^{20}$ have been identified as m6A readers. In addition to the direct effects of m6A on RNA, m6A-modificationinduced signaling is mediated by these $\mathrm{YTH}$-family proteins to regulate various cellular responses and cell fate decisions.
The methyl group of m6A can be removed by two RNA demethylases, fat mass and obesity-associated protein (FTO) and $\alpha$-ketoglutarate-dependent dioxygenase homologue 5 (ALKBH5)..$^{21-23}$ They are members of the non-heme $\mathrm{Fe}(\mathrm{II}) / 2$-oxoglutarate (2OG)-dependent dioxygenase superfamily associated with regulation of protein synthesis. ${ }^{21}$ ALKBH5 is predominantly localized to nuclear speckles and therefore likely demethylates $\mathrm{m} 6 \mathrm{~A}$ in nascent RNA or in premRNA in the nucleus. ${ }^{22,23}$ Unlike FTO, ALKBH5 has no activity toward N-6,2'-O-dimethyladenosine (m6Am). Several crystal structures of the ALKBH5 catalytic domain have been reported, either bound to 2-oxoglutarate or to an inhibitor. $^{21,24,25}$ ALKBH5 demethylates ssRNAs and ssDNAs that contain $\mathrm{m} 6 \mathrm{~A}$ residues, and its activity is, to a minor degree, inhibited by citrate. ${ }^{21}$ The available structural data facilitate the rational design of new specific ALKBH5 inhibitors and activators based on the established binding pocket of this protein. Specific and efficient ALKBH5 inhibitors or activators would enable a closer examination of the physiological and pathological processes related to the $\mathrm{m} 6 \mathrm{~A}$ demethylation of RNA. $^{26}$

Received: March 10, 2021

Accepted: May 5, 2021

Published: May 14, 2021 
Table 1. Compounds with the Highest Docking Efficiencies to RNA m6A Demethylase ALKBH5

\begin{tabular}{|c|c|c|c|}
\hline No. & Compound structure & $\Delta \mathrm{G}(\mathrm{kcal} / \mathrm{mol})$ & $\mathbf{L E}$ \\
\hline$\underline{1}$ & & -8.70 & 0.51 \\
\hline$\underline{2}$ & & -8.13 & 0.21 \\
\hline$\underline{\mathbf{3}}$ & & -6.53 & 0.44 \\
\hline$\underline{4}$ & & -7.83 & 0.39 \\
\hline$\underline{5}$ & & -7.08 & 0.47 \\
\hline$\underline{6}$ & & -4.78 & 0.32 \\
\hline
\end{tabular}

Data accumulated during the past few years have linked abnormalities in ALKBH5 functionality to different cancer types (cf. Table S1). Depending on the cancer type, ALKBH5 may act as either a cancer promoter or a cancer suppressor. ${ }^{27,28}$ In some cases, the ALKBH5 expression has been associated with that of other regulatory genes, while in some cases, ALKBH5 activity has been associated with specific target mRNAs (cf. Table S2).

For instance, it has been shown that ALKBH5 is inducible by hypoxia-inducible factor 1 (HIF-1) in different cells. ${ }^{29} \mathrm{~A}$ hypoxic microenvironment, a common feature to various tumors, promotes cancer progression. ALKBH5 has been reported to promote tumorigenesis and proliferation in glioblastoma stem-like cells (GSCs), ${ }^{30}$ breast cancer stem cells (BCSCs), ${ }^{31}$ and $\mathrm{SiHa}$ human cervical cancer cells. ${ }^{32}$ Furthermore, the cells' motility was also increased by ALKBH5. Thus, since ALKBH5-mediated reduction of RNA m6A levels promotes cancer cell proliferation, increasing $\mathrm{m} 6 \mathrm{~A}$ levels through inhibition of ALKBH5 may have anticancer effects. ${ }^{32}$ It has also been shown that deletion of ALKBH5 sensitized melanoma and colorectal cancer tumors to cancer immunotherapy. ${ }^{33}$ Furthermore, inhibition of ALKBH5 suppressed tumor growth combined with PD-1 and GVAX immunotherapy in mice. ${ }^{33} \mathrm{~A}$ recent analysis of tissue microarray of the tumors in 177 esophageal squamous cell carcinoma ESCC patients has shown that higher expression of ALKBH5 correlated with poor prognosis. Moreover, the authors identified the expression of ALKBH5, but not FTO, as an independent prognostic factor for patient survival. ${ }^{34}$

The reported abnormalities in the expression of ALKBH5 in cancer cells and its participation in tumorigenesis are summarized in Table S1. From these data, it is evident that the change in ALKBH5 can be both oncogenic and cancersuppressing, depending on the type of cancer. Such complexity of the m6A regulation in cancer has been recently demonstrated in a study of the relationship between ALKBH5 and hepatocellular carcinoma (HCC). ${ }^{35}$ Contrary to the above examples, it was found that ALKBH5 was downregulated in HCC. Poor patient survival correlated with lower levels of ALKBH5. Experimentally, increased ALKBH5 expression was able to reduce HCC cell proliferation and invasiveness. The authors concluded that mechanistically, 

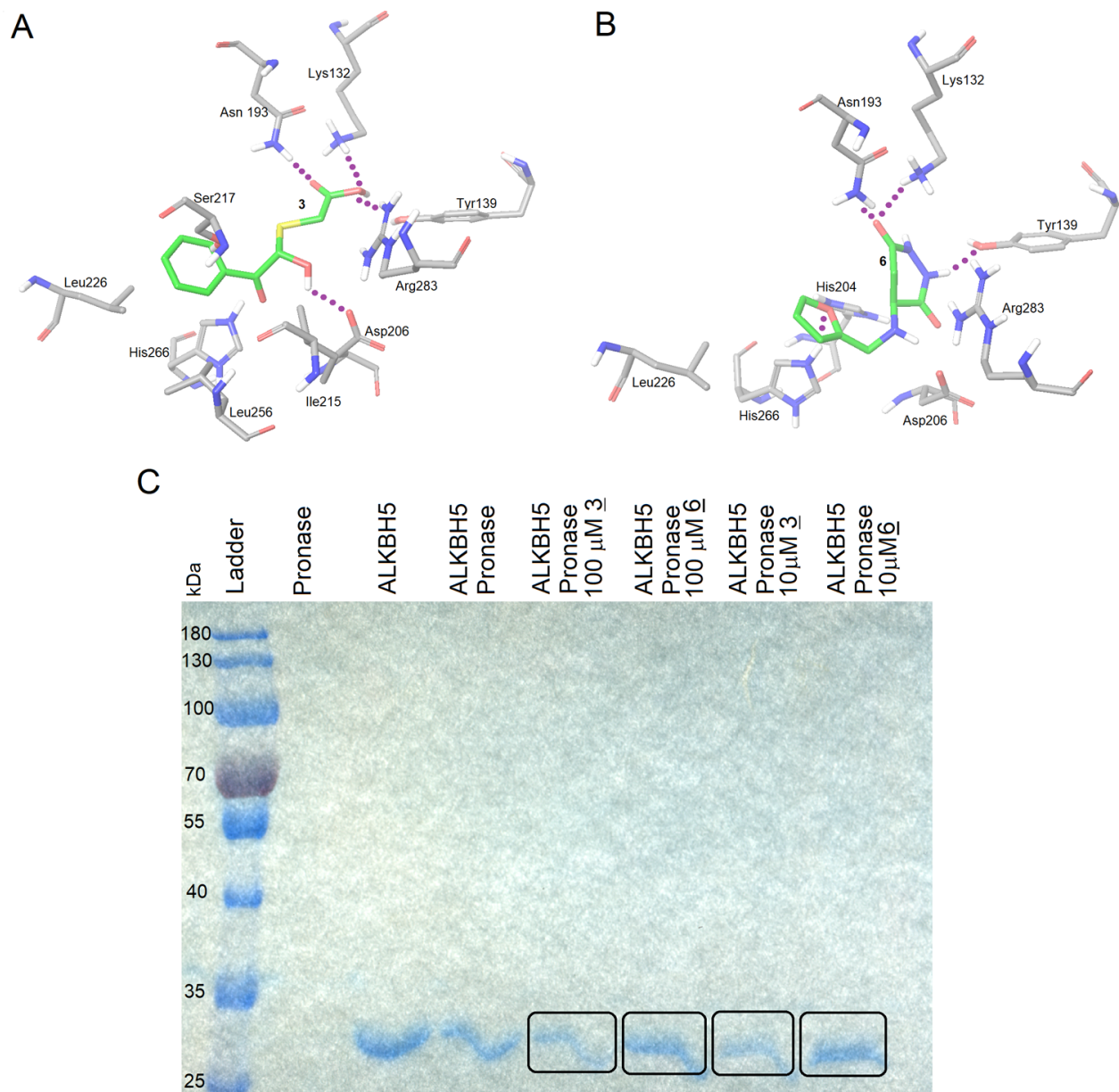

Figure 1. Binding compounds to ALKBH5 protein. (A) Docking binding position of compound 3 at the active center of ALKBH5 protein. (B) Docking binding position of compound 6 at the active center of ALKBH5 protein. (C) PageBlue Protein Staining visualization of unbiased DARTS of ALKBH5 protein treated with compounds 3 and $\mathbf{6}$ at 10 and $100 \mu \mathrm{M}$ concentrations.

reduced ALKBH5 activity led to increased levels of m6A on LY6/PLAUR domain-containing 1 (LYPD1) mRNA. The m6A-methylated transcripts were recognized by the m6A effector insulin-like growth factor 2 mRNA binding protein 1 (IGF2BP1) leading to stabilization of LYPD1 mRNA and increased LYPD1 protein expression promoting HCC tumorigenicity. Furthermore, downregulation of ALKBH5 has been observed in pancreatic cancer cells ${ }^{36-38}$ and colon cancer cells; $^{39}$ thus, this $\mathrm{m} 6 \mathrm{~A}$ demethylase is expected to act as a tumor suppressor also in these cases.

However, in most cases, ALKBH5 has been recognized as an oncogene. ${ }^{40-46}$ Recently, it has been shown that similarly to the other RNA m6A demethylase FTO, ${ }^{47,48}$ ALKBH5 is abnormally overexpressed in acute myeloid leukemia (AML) and this overexpression correlates with poor prognosis in AML patients. ${ }^{49}$ Although ALKBH5 is not essential for normal hematopoiesis, it was necessary for self-renewal of leukemia stem or initiating cells (LSCs/LICs) and for the development and persistence of AML. ALKBH5 acts post-transcriptionally on its critical targets such as transforming acidic coiled-coil containing protein 3 (TACC 3 ), a prognosis-associated oncogene in various cancers. ${ }^{48,49}$ Earlier, a high significance of the ALKBH5 expression has been reported in glioblastoma stem cells (GBMSCs). It was shown that the demethylase ALKBH5 is highly expressed in GSCs, as well as in established glioblastoma cell lines. ${ }^{30}$ It has been shown recently that a new sodium channel blocker imidazobenzoxazin-5-thione MV1035 significantly reduces U87 cell line migration and invasiveness by inhibiting ALKBH5 enzymatic activity at the micromolar level. $^{50}$ Very recently, it was shown that m6A RNA demethylase ALKBH5 promotes the radioresistance of GBMSCs by controlling the homologous repair and influences GBMSC invasion. ${ }^{51}$

Therefore, it can be concluded that present knowledge supports the hypothesis that the compounds inhibiting ALKBH5 activity can act as suppressors of different types of cancer. $^{52}$ Two attractive targets would be AML and glioblastoma, one of which represents a liquid and another a solid tumor. Notably, very recently small-molecule inhibitors of another RNA m6A demethylase acting as AML suppressors were reported. ${ }^{53}$ Thus, in this work, our aim was to design and identify effective ALKBH5 inhibitors and test their activity against selected AML and GSC lines.

\section{RESULTS AND DISCUSSION}

A virtual screening using the Glide VSW module of Schrödinger was carried out for the compounds from the FIMM compound library (HTB, 2018). A virtual screening on the FIMM compound library (HTB, 2018) containing $\sim 144000$ compounds was carried out using nitrogencontaining heterocycles as base structures. As a result, six different compounds with the highest docking free energies 

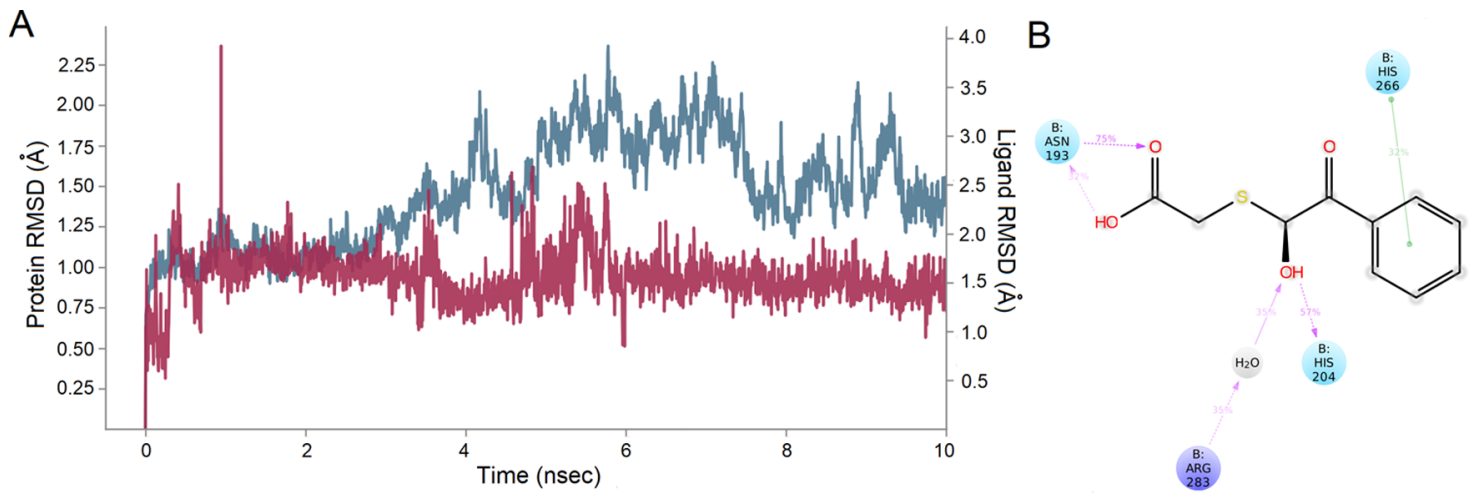

C
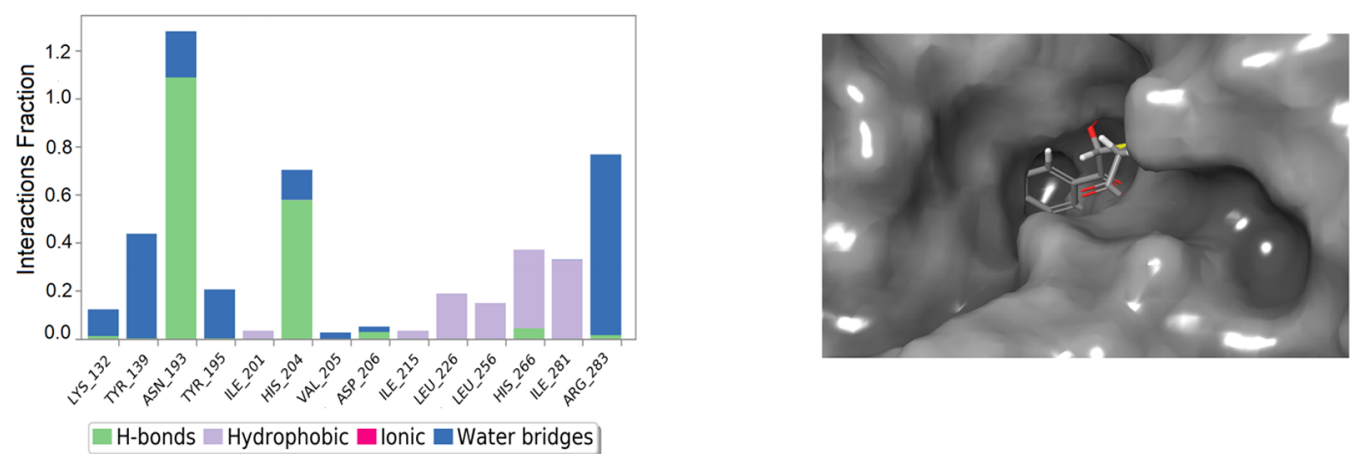

Figure 2. Results of the molecular dynamics simulation of ALKBH5 in complex with compound 3. (A) Protein and ligand position root-meansquare deviation (RMSD) plot against time in the case of the ALKBH5 with compound 3 for 10 ns runs. (B) Normalized stacked bar chart of interactions and contacts between the protein and ligand over the course of trajectory; interactions occurring more than $30 \%$ of the simulation time. Interaction diagram between compound 3 and ALKBH5. (C) Desmond 2D profile data for compound 3 binding to ALKBH5. (D) Position of compound 3 in the structure of ALKBH5.

and/or ligand efficiencies were selected to study interactions between compounds and protein.

The docking free energies $(\Delta G)$ and ligand efficiencies (LE) of the best binding compounds, and their molecular structures are given in Table 1 .

Interactions between a ligand and ALKBH5 protein were found by carrying out the molecular docking using AutoDock 4.2. As shown by the molecular docking calculations, the amino acid residues of the protein Lys132, Tyr139, Asn193, Asp206, His204, and Arg283 were involved in specific interactions between the protein and ligand (Figure 1).

The molecular dynamics simulations were carried out for two compounds, 3 and $\mathbf{6}$, the compounds with the best enzymatic inhibition activity. In the case of compound 3, several molecular dynamics simulation runs were carried out with a length of $10 \mathrm{~ns}$. This system was stable throughout the calculation time (Figure 2A). Strong hydrogen bonds were detected between the compound 3 carboxyl group atoms and the ammonium group of Asn 193 residue of ALKBH5 protein (Figure 2B). The simulation interactions diagram (Figure 2C) indicates that the most important interactions for this compound are hydrogen bonds between the ligand and the residues Asn193 and His204 of ALKBH5. There are additional water bridges and hydrophobic interactions between ligand 3 and ALKBH5 protein. The bars in the diagram (Figure 2C) characterize the time fraction that a particular specific interaction is maintained during the simulation. Based on this, we can assume that compound 3 is bound to the active site of ALKBH5 protein (Figure 2D).

The results of the molecular dynamics simulation of compound $\mathbf{6}$ are shown in Figure 3. Again, several molecular dynamics simulation runs were carried out with a length of 10 ns, and the trajectory analysis shows the stability of the system during the calculation (Figure 3A). There is one strong hydrogen bond between the ligand and His204 residue of ALKBH5 protein. In addition, a water bridge with Tyr195, His204, and Asp206 is suggested (Figure 3B,C). Compound 6 is bound to a tight specific pocket in the active site of ALKBH5 protein (Figure 3D).

The binding of inhibitory compounds to ALKBH5 was studied using the drug affinity responsive target stability (DARTS) measurements. The results given in Figure 1C indicate a substantial effect of compound 3 on the stability of the protein that reflects the binding of this compound. In the case of compound 6 , this effect is significantly smaller.

The inhibition of ALKBH5 RNA m6A demethylation activity was experimentally studied for the six compounds with the highest docking efficiency (Table 1). Significant inhibitory activity was observed in the case of two compounds. The dependence of the inhibitory effect (IE) on the inhibitor concentration for compounds $\mathbf{3}$ and $\mathbf{6}$ is shown in Figure 4.

The inhibitory concentrations are $\mathrm{IC}_{50}=0.84 \mu \mathrm{M}$ for compound 3 and $\mathrm{IC}_{50}=1.79 \mu \mathrm{M}$ for compound 6 , demonstrating that both compounds are efficient inhibitors of the RNA m6A demethylase ALKBH5. These compounds were then used in further studies as potential antiproliferative agents for their cancer cell growth-suppressing activities.

The antiproliferative effects of the developed ALKBH5 inhibitors on cancer cells were studied using four leukemia cell lines and one glioblastoma cell line. The selection of cancer type was based on earlier observations stating that the overexpression of the ALKBHS gene in leukemia and 
A

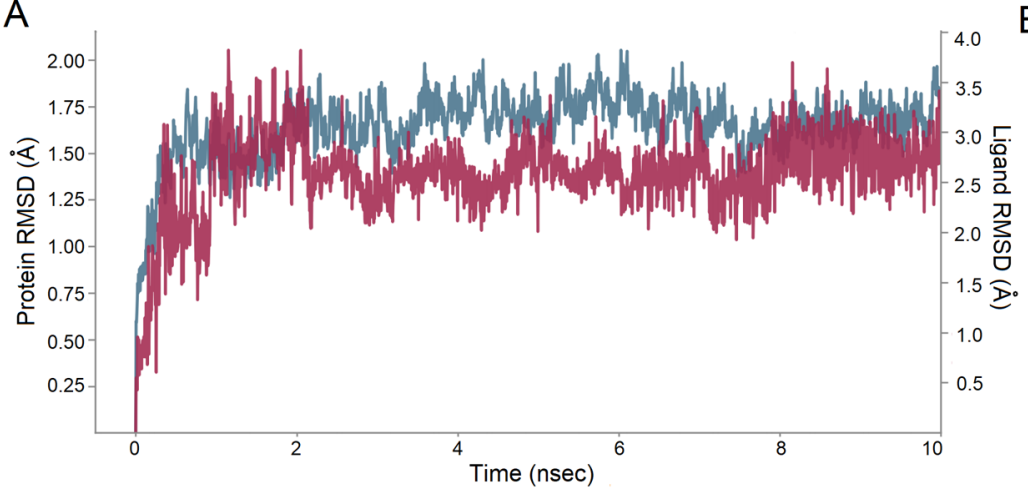

B

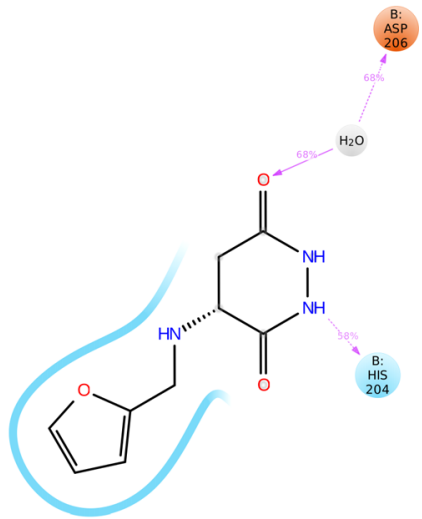

C
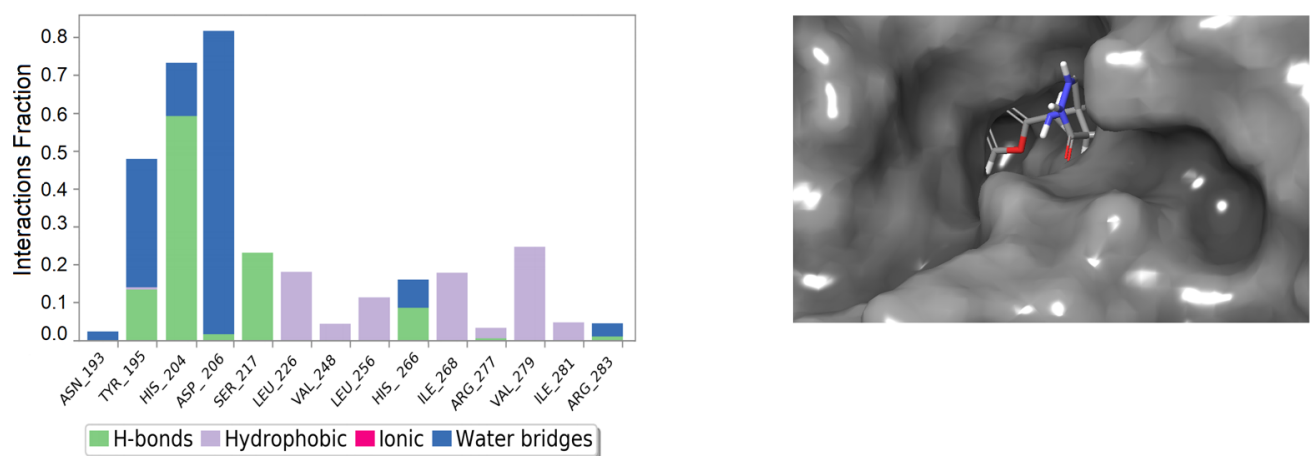

Figure 3. Results of the molecular dynamics simulation of ALKBH5 in complex with compound 6. (A) Protein and ligand position root-meansquare deviation (RMSD) plot against time in the case of the ALKBH5 with compound 6 for 10 ns runs. (B) Normalized stacked bar chart of interactions and contacts between the protein and ligand over the course of trajectory; interactions occurring more than $30 \%$ of the simulation time. Interaction diagram between compound 6 and ALKBH5. (C) Desmond 2D profile data for compound 6 binding to ALKBH5. (D) Position of compound 6 in the structure of ALKBH5.
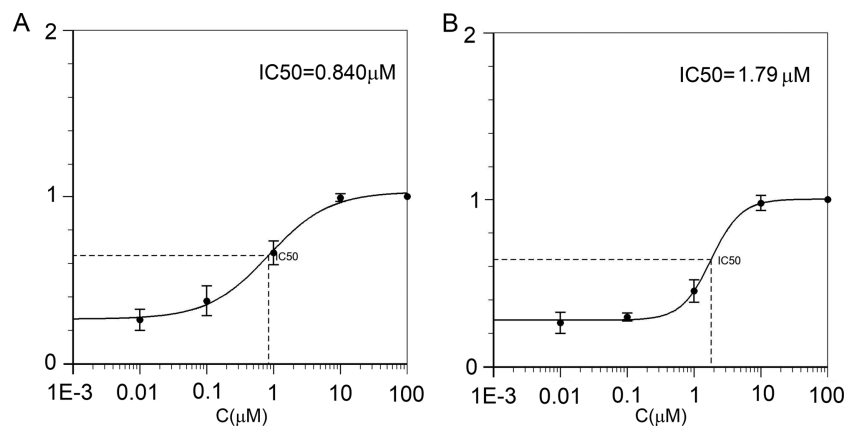

Figure 4. Inhibitory effect (IE) of compounds 3 (A) and 6 (B) on the demethylation of the probe RNA by ALKBH5.

glioblastoma patients was correlated with poor prognosis of the disease. $^{30,49}$ The cell lines selected for further study are briefly characterized in Table 2.

The time dependence of the inhibitory effects of compounds 3 and $\mathbf{6}$ on the cell viability at different concentrations are given in Figures 5 and 6, respectively. Cell viability under treatment with a compound was calculated as the ratio of the number of cells in the compound treated to the number of untreated cells in the presence of corresponding vehicle.

$$
\text { viability } \%=\frac{N(\text { compound })}{N(\text { no compound })}
$$

In the case of all studied cell lines, a strong toxic effect of compounds was observed starting from $1 \mathrm{mM}$ concentrations, developing rapidly after the treatment with a compound. We
Table 2. Cell Lines Studied

\begin{tabular}{|c|c|c|c|c|}
\hline cell line & disease & $\begin{array}{l}\text { NCI } \\
\text { thesaurus } \\
\text { code }\end{array}$ & $\begin{array}{l}\text { gender } \\
\text { of cell }\end{array}$ & age at sampling \\
\hline $\begin{array}{l}\text { HEK- } \\
293 \mathrm{~T}\end{array}$ & $\mathrm{n} / \mathrm{a}$ & $\mathrm{n} / \mathrm{a}$ & female & fetus \\
\hline HL-60 & $\begin{array}{l}\text { adult acute myeloid } \\
\text { leukemia }\end{array}$ & C9154 & female & 35 years \\
\hline $\begin{array}{l}\text { CCRF- } \\
\text { CEM }\end{array}$ & $\begin{array}{l}\text { childhood } \mathrm{T} \text { acute } \\
\text { lymphoblastic } \\
\text { leukemia }\end{array}$ & C7953 & female & 3 years 11 months \\
\hline Jurkat & $\begin{array}{l}\text { childhood } \mathrm{T} \text { acute } \\
\text { lymphoblastic } \\
\text { leukemia }\end{array}$ & C7953 & male & 14 years \\
\hline K562 & $\begin{array}{l}\text { chronic myelogenous } \\
\text { leukemia, BCR- } \\
\text { ABL1-positive }\end{array}$ & C 3174 & female & 53 years \\
\hline A-172 & glioblastoma & C3058 & male & 53 years \\
\hline
\end{tabular}

therefore examined the inhibitory effects of the compounds in the range of $1-100 \mu \mathrm{M}$, i.e., at the concentrations where the inhibition was registered in the enzymatic assay. Notably, both compounds 3 and 6 demonstrated significant antiproliferative effects on the HEK-293T cells at $100 \mu \mathrm{M}$ concentration (Figures 5A and 6A). At lower concentrations, the compounds had no effects on these cells. However, inhibitory effects of compounds at lower concentrations were observed for leukemia cell lines (HL-60, CCRF-CEM, and K562). In most cases, the effects were already notable when measured at $4 \mathrm{~h}$ during the treatment of the cell cultures with the compounds and lasting throughout the $48 \mathrm{~h}$ experiment. 

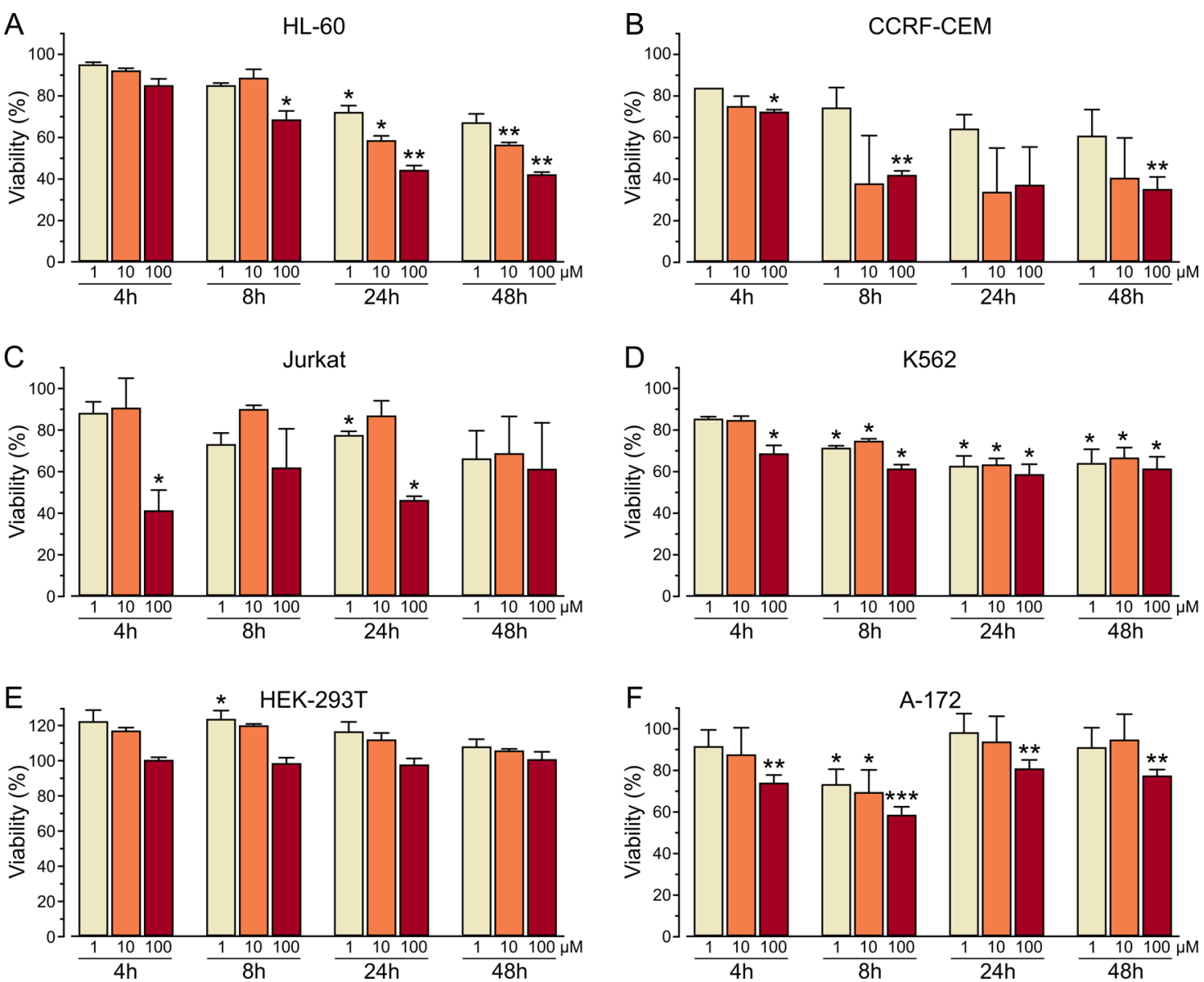

Figure 5. Time dependence of cell viability at different concentrations of the ALKBH5 inhibitor 3. (A) HEK-293T; (B) HL-60; (C) CCRF-CEM; (D) Jurkat; (E) K562; (F) A-172. Data presented as mean \pm SD. $* p<0.05, * * p<0.01, * * * p<0.001$, two-way analysis of variance (ANOVA) test.

Contrary to the expectations from the earlier work showing oncogenic character of the ALKBH5 in the case of glioblastoma, ${ }^{30}$ the inhibitory effect of our ALKBH5 inhibitors on the viability of the glioblastoma A-172 cells was negligible (cf. Figures $5 \mathrm{~F}$ and $6 \mathrm{~F}$ ). This is in accordance with the recently published results on the inhibition of a different glioblastoma cell line, U87-MG cells with another ALKBH5 inhibitor, imidazobenzoxazin-5-thione (MV1035), where practically no effect of this effect on the cell viability was reported. ${ }^{50}$ The inhibitory concentrations $\mathrm{IC}_{50}$ of compounds 3 and 6 on different cell lines are presented in Table 3.

Keeping in mind the diversity of the effects of the m6A on different cancers, ${ }^{54,55}$ the variability in the effects of the ALKBH5 inhibitors is not unexpected. However, further studies will be necessary to understand the detailed differences in the regulation of RNA m6A methylation and its contribution to mitogenic control in cancer and normal cells.

\section{MATERIALS AND METHODS}

3.1. Computational Modeling. The search for the RNA m6A demethylase ALKBH5 binding compounds was carried out based on the available protein crystal structures. The structure of the RNA m6A demethylase ALKBH5 (PDB: 4O61) had been measured by X-ray diffraction with resolution $1.9 \AA^{21}{ }^{21}$ This crystal structure was edited by automatic addition of missing hydrogen atoms to the protein using Schrödinger's Protein Preparation Wizard of Maestro 10.7..$^{56}$ The virtual screening was carried out based on molecular docking to find compounds from the FIMM compound library (HTB, 2018) database with the best docking scores using Glide Virtual Screening Workflow (VSW) module of the Schrödinger suite 2015 and AutoDock 4.2. ${ }^{57}$ AutoDock 4.2 ${ }^{57}$ was used for the docking studies to find out binding energies and binding modes of small-molecule ligands to the protein. The number of rotatable bonds of ligand was set by default according to the AutoDockTools 1.5.6. ${ }^{57}$ When the number of rotatable bonds exceeded six, some of these were fixed. A grid box of dimension $70 \times 70 \times 70$ points with a spacing of $0.375 \AA$ was used as surrounding the active site of the enzyme. In all molecular docking simulations, the AutoDock 4.2 force field was used. The binding of the small molecules to the protein was characterized by ligand efficiencies (LE), calculated as follows

$$
\mathrm{LE}=-\frac{\Delta G_{\mathrm{dock}}}{N}
$$

where $\Delta G_{\text {dock }}$ is the docking free energy and $N$ is the number of nonhydrogen ("heavy") atoms in the small molecule.

The geometrical structure of ligand molecules was optimized using the density functional theory B3LYP method ${ }^{58}$ with the 6-31G basis set.

Ten molecular dynamics simulation runs with a length of 10 ns and relaxation time of 1 ps were carried out for each complex of ALKBH5 protein with compounds 3 and $\mathbf{6}$, respectively. The molecular dynamics simulations were carried out using the Desmond simulation package of Schrödinger 

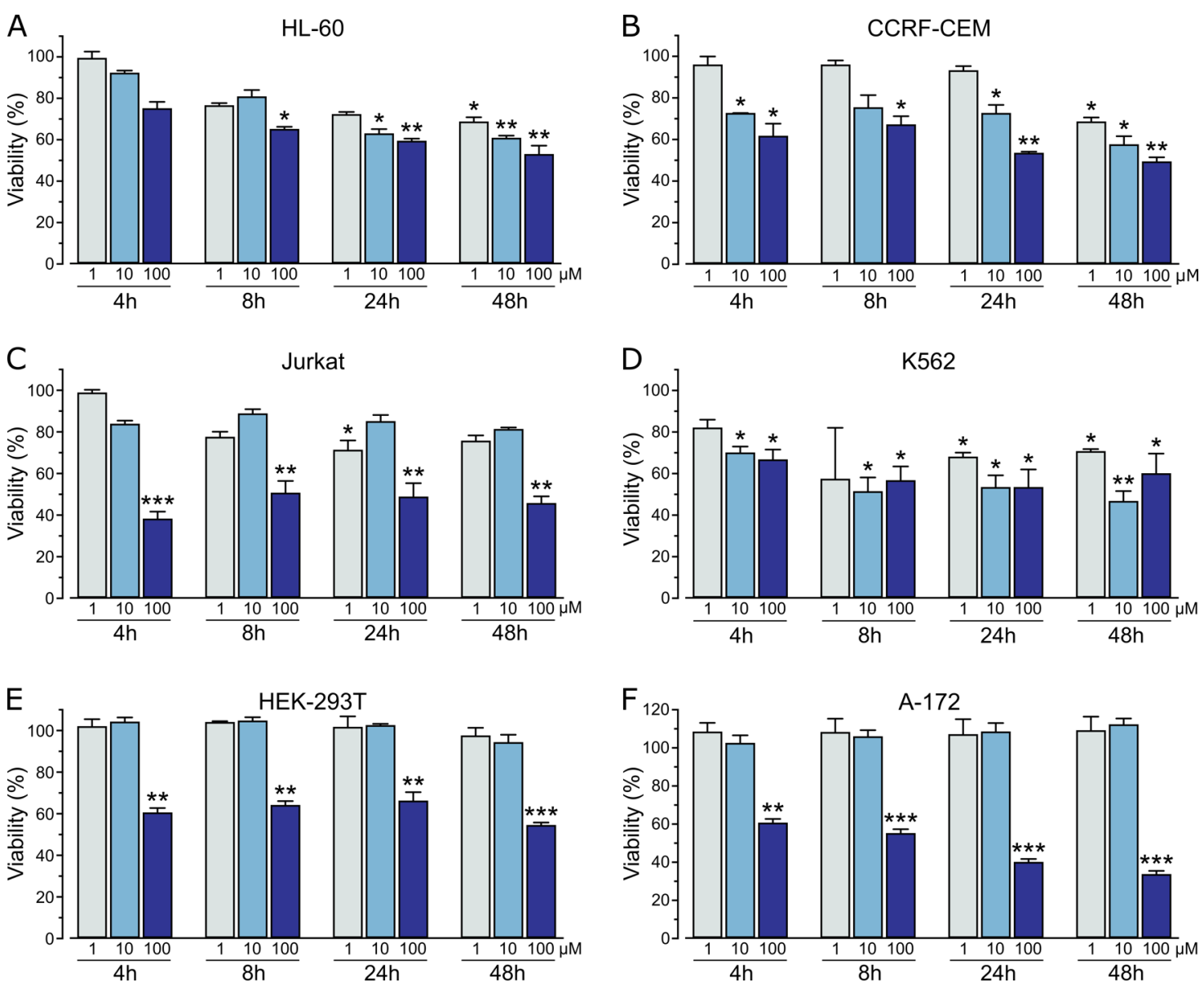

Figure 6. Time dependence of cell viability at different concentrations of the ALKBH5 inhibitor 6. (A) HEK-293T; (B) HL-60; (C) CCRF-CEM; (D) Jurkat; (E) K562; (F) A-172. Data presented as mean \pm SD. $*_{p}<0.05, * * p<0.01$, ***p $<0.001$, two-way ANOVA test.

Table 3. Inhibitory Concentrations $\mathrm{IC}_{50}$ of Compounds 3 and 6 on Different Cell Lines ${ }^{a}$

\begin{tabular}{lcc}
\multicolumn{1}{c}{ cell line } & compound 3, $\mathrm{IC}_{50}(\mu \mathrm{M})$ & compound 6, $\mathrm{IC}_{50}(\mu \mathrm{M})$ \\
HEK-293T & $>50$ & $40.5 \pm 13.1$ \\
CCRF-CEM & $1.38 \pm 0.30$ & $7.62 \pm 2.61$ \\
HL-60 & $11.9 \pm 2.3$ & $11.0 \pm 2.7$ \\
Jurkat & $47.8 \pm 28.3$ & $41.3 \pm 4.7$ \\
K562 & $16.5 \pm 2.1$ & $1.41 \pm 0.12$ \\
A-172 & $>50$ & $>50$
\end{tabular}

${ }^{a_{T}}$ The $\mathrm{IC}_{50}$ values are calculated as average from time points $4,8,24$, and $48 \mathrm{~h}$.

LLC. $^{59}$ The NPT ensemble with a temperature of $300 \mathrm{~K}$ and pressure of 1 bar was applied in all runs. Ten simulation runs with a length of $10 \mathrm{~ns}$ and relaxation time of 1 ps were carried out for each system. The OPLS_2005 force field parameters were used in all simulations. ${ }^{60}$ The long-range electrostatic interactions were calculated using the particle mesh Ewald method. ${ }^{61}$ The cutoff radius in Coulomb interactions was 9.0 $\AA$. The water molecules were described using the simple point charge (SPC) model. ${ }^{62}$ The behavior and interactions between the ligands and enzyme were analyzed using the Simulation Interaction Diagram tool implemented in Desmond molecular dynamics package. The stability of molecular dynamics simulations was monitored by the root-mean-square deviation (RMSD) of the ligand and protein atom positions in time.
3.2. Compounds. (1) 3-(5-Chloro-1,3-dioxo-2,3,3a,4,7,7ahexahydro-1H-isoindol-2-yl)propanoic acid (ChemBridge Corporation, San Diego, CA, Cat. No. 5814560, purity: 90\%). (2) (2Z)-3-[(2H-1,3-benzodioxol-5-yl)methyl]-2-[(4ethoxyphenyl)imino]-N-(2-methoxy-phenyl)-4-oxo-1,3-thiazinane-6-carboxamide (ChemDiv, Inc., San Diego, CA, Cat. No. 2738-0165, purity: >90\%). (3) 2-[(1-Hydroxy-2-oxo-2phenylethyl)sulfanyl]acetic acid (Enamine Ltd., Monmouth Jct., NJ, Cat No. EN300-14040, purity: >90\%). (4) 3-[1-(3Chloro-4-methylphenyl)-2,5-dioxoimidazolidin-4-yl]propanoic acid (Enamine Ltd., Cat No. Z234897619, purity: >90\%). (5) 2-(1,3-Benzothiazol-2-ylsulfanyl)propanoic acid (Specs Compound Handling B.V., Zoetermeer, The Netherlands, Cat. No. AI-204/31680041, purity: 90\%). (6) 4-\{[(Furan-2-yl)methyl $]$ amino\}-1,2-diazinane-3,6-dione (Vitas-M Laboratory, Ltd., Causeway Bay, Hong Kong, Cat. No. STL352808, purity: $>90 \%)$.

3.3. Cell Lines. Embryonic kidney cells HEK-293T (CRL1573), childhood $\mathrm{T}$ acute lymphoblastic leukemia cells CCRFCEM (CRM-CCL-119), adult acute myeloid leukemia HL-60 (CCL-240), and immortalized $\mathrm{T}$ lymphocyte Jurkat cells (CRL-2899) were all obtained from ATCC (Manassas, VA).

3.4. ALKBH5 Protein Synthesis. The synthesis of ALKBH5 protein was carried out using the baculovirus expression method. The protocol of the synthesis and purification of the protein is given in the Supporting Information (Part II). 
3.5. Drug Affinity Responsive Target Stability (DARTS) Measurement of Ligand Binding. The DARTS experiment was modified from Pai et al. ${ }^{63}$ Solutions of the studied ALKBH5 inhibitors 3 and 6, the ALKBH5 truncated protein (66-292), and pronase were prepared using TNC buffer. All samples contained $5 \mu \mathrm{g}$ of ALKBH5 protein, and inhibitors were added at concentrations 100 and $10 \mu \mathrm{M}$. All protein and inhibitor samples were incubated $2 \mathrm{~h}$ at RT. After incubation, $0.05 \mu \mathrm{g}$ of Pronase (Sigma-Aldrich) was added and incubated at RT for $10 \mathrm{~min}$ and stopped by adding protease inhibitor. The $2 \times$ sodium dodecyl sulfate-polyacrylamide gel electrophoresis (SDS-PAGE) sample buffer (Laemelli buffer) was added to the protein solutions to yield a $1 \times$ sample buffer concentration, and all samples were incubated for $5 \mathrm{~min}$ at 100 ${ }^{\circ} \mathrm{C}$. Samples $(15 \mu \mathrm{L})$ and prestained SDS-PAGE standard (5 $\mu \mathrm{L}$ ) were loaded into $10 \%$ polyacrylamide gel. Electrophoresis was carried out for $55 \mathrm{~min}$ at RT using a voltage of $200 \mathrm{~V}$ in a $1 \times$ SDS running buffer. The gel was stained thereafter using PageBlue Protein Staining Solution (Thermo Scientific).

3.6. Enzyme Inhibition. The enzymatic assay was applied as described by Huang et al., ${ }^{64}$ except using ALKBH5 instead of FTO as the RNA demethylating enzyme. The experiments were conducted in reaction buffer ( $50 \mathrm{mM}$ Tris- $\mathrm{HCl}, \mathrm{pH} 7.5$, $300 \mu \mathrm{M} 2 \mathrm{OG}, 280 \mu \mathrm{M}\left(\mathrm{NH}_{4}\right)_{2} \mathrm{Fe}\left(\mathrm{SO}_{4}\right)_{2}$ and $2 \mathrm{mM}$ L-ascorbic acid). The reaction mixture contained $200 \mathrm{ng}$ of methylated N6-adenine RNA probe (5'-CUUGUCAm6ACAGCAGA-3', PerkinElmer Horizon Discovery Ltd., Dharmacon, Cambridge, U.K.) and $10 \mathrm{nM}$ ALKBH5 protein. Reactions were incubated on a 96-well plate for $2 \mathrm{~h}$ at RT. After that, m6A was measured using EpiQuik m6A RNA methylation Quantification Colorimetric Kit (Epigentek Group, Inc., Farmingdale, NY). The inhibitory effect (IE) of compounds on RNA probe demethylation by ALKBH5 was calculated as the increase in the amount of $\mathrm{m} 6 \mathrm{~A}$ compared to the negative control (dimethyl sulfoxide (DMSO)) relative to the difference between the amounts of $\mathrm{m} 6 \mathrm{~A}$ of the positive control ( $\max$ inhibition) and the negative control (eq 3)

$$
\mathrm{IE}=\frac{C_{\text {inh }}-C_{\text {DMSO }}}{C_{\text {inh }}(\max )-C_{\text {DMSO }}}
$$

where $C_{\text {inh }}, C_{\text {inh }}(\max )$, and $C_{\text {DMSO }}$ are the amounts of m6A at a given concentration of the inhibitor, maximum inhibition, and in the case of DMSO, respectively.

3.7. Leukemia Cell Lines Assay. The Childhood T acute lymphoblastic leukemia cell line CCRF-CEM and Jurkat cells were grown in Roswell Park Memorial Institute medium 1640 (RPMI 1640; Thermo Fisher Scientific Invitrogen, Waltham, MA) supplemented with $10 \%$ heat-inactivated fetal bovine serum (FBS; Thermo Fisher Scientific Invitrogen, Waltham, MA) and penicillin/streptomycin. HL-60 cells were grown in Iscove's modified Dulbecco's medium (Thermo Fisher Scientific Invitrogen, Waltham, MA) supplemented with $20 \%$ heat-inactivated FBS and penicillin/streptomycin. K562 cells were also grown in Iscove's modified Dulbecco's medium (Thermo Fisher Scientific Invitrogen, Waltham, MA), but supplemented with $10 \%$ heat-inactivated FBS and penicillin/ streptomycin.

A total of $1 \times 10^{5}$ CCRF-CEM, HL-60, K562, and Jurkat cells were seeded separately in $1 \mathrm{~mL}$ on a 24 -well plate. The cells were grown for $48 \mathrm{~h}$ with added compounds at given concentrations, and $0.5 \%$ DMSO was used as a vehicle control. The cells were counted at time points $0,4,8,24$, and $48 \mathrm{~h}$. Cell viability was measured using Countess Automated Cell Counter (Thermo Fisher Scientific Invitrogen, Waltham, MA).

HEK-293T and A-172 cells were grown in Dulbecco's modified Eagle's medium (Thermo Fisher Scientific Invitrogen, Waltham, MA) supplemented with $10 \%$ heat-inactivated FBS and penicillin/streptomycin. HEK-293T $\left(8 \times 10^{3}\right)$ and A172 cells $\left(1 \times 10^{3}\right)$ were seeded in $200 \mu \mathrm{L}$ on a 16 -well E-plate. The cells were grown for $48 \mathrm{~h}$ with added compounds at given concentrations, and $0.5 \%$ DMSO was used as a vehicle control. Cell viability was measured in real time using an xCELLigence machine (RTCA xCELLigence, Agilent Technologies, Inc., Santa Clara, CA). The data at time points $0,4,8,24$, and $48 \mathrm{~h}$ were extracted for further analysis. All cells were grown in a humidified atmosphere at $37{ }^{\circ} \mathrm{C}$ in the presence of $5 \% \mathrm{CO}_{2}$.

3.8. Quantification and Statistical Analysis. Enzymatic assay and cell viability curve-fitting analysis and determination of the $\mathrm{IC}_{50}$ values were performed using a Quest Graph $\mathrm{IC}_{50}$ Calculator (v.1, AAT Bioquest, Inc., Sunnyvale, CA). Statistical significance in cell survival experiments was assessed using oneway ANOVA and unpaired $t$ test with the GraphPad Prism8 software (GraphPad Software, Inc., San Diego, CA). Results were considered statistically significant at $p<0.05$.

\section{CONCLUSIONS}

In the present work, we report the computer-aided development of active inhibitors of the RNA m6A demethylase ALKBH5. Using an m6A antibody-based enzymatic assay, two low micromolar active inhibitors belonging to different chemical scaffolds were identified among the in silico-predicted compounds. The compounds 2-[(1-hydroxy-2-oxo-2phenylethyl)sulfanyl $]$ acetic acid (3) and $4-\{[$ (furan-2-yl)methyl]amino -1,2-diazinane-3,6-dione (6) were applied on cultures of different cancer cell lines to study the effects of ALKBH5 inhibition on cell viability. Six cell lines were chosen for this study: four leukemia cell lines (HL-60, CCRF-CEM, K562, and Jurkat), one glioblastoma cell line (A-172), and human embryonic kidney (HEK-293T) cell line. In the case of three cell lines (HL-60, CCRF-CEM, and K562), the viability of the cells was reduced from $100 \%$ down to about $40 \%$ by both ALKBH5 inhibitors studied at low micromolar concentrations. A much smaller effect was registered in the case of Jurkat cells.

In conclusion, the ALKBH5 inhibitors reported in the present work could be valuable for further deeper studies of the RNA 6-N-methylation regulation both in normal and pathological cells. Further optimization of the chemical structure of the compounds may lead to high-potency ALKBH5 inhibitors attractive for further drug development against cancer.

\section{ASSOCIATED CONTENT}

\section{Supporting Information}

The Supporting Information is available free of charge at https://pubs.acs.org/doi/10.1021/acsomega.1c01289.

ALKBH5 as related to cancer; ALKBH5 and cancer (Table S1); ALKBH5-related target genes in cancer (Table S2); and ALKBH5 protein synthesis The data presented in this study are available on request from the corresponding author. (PDF) 


\section{AUTHOR INFORMATION}

\section{Corresponding Author}

Mati Karelson - Institute of Chemistry, University of Tartu, Tartu 50411, Estonia; 이이이.org/0000-0002-9643-6380; Email: mati.karelson@ut.ee

\section{Authors \\ Simona Selberg - Institute of Chemistry, University of Tartu, Tartu 50411, Estonia \\ Neinar Seli - Chemestmed, Ltd., Tartu 50411, Estonia \\ Esko Kankuri - Faculty of Medicine, Department of Pharmacology, University of Helsinki, Helsinki 00014, Finland; O orcid.org/0000-0002-2193-8773}

Complete contact information is available at: https://pubs.acs.org/10.1021/acsomega.1c01289

\section{Author Contributions}

S.S. contributed to computational modeling, virtual screening, enzyme inhibition experiments, cell viability experiments, and data analysis. N.S. performed funding acquisition and data analysis. M.K. performed coordination of the study and data analysis. M.K., S.S., and E.K. involved in writing and editing the manuscript.

\section{Funding}

This research was funded by Chemestmed, Ltd.

\section{Notes}

The authors declare no competing financial interest.

\section{ACKNOWLEDGMENTS}

The authors gratefully acknowledge Ivar Ilves for providing ALKBH5 protein and help by Eva Žusinaite in DARTS experiment.

\section{REFERENCES}

(1) Song, J.; Yi, C. Chemical Modifications to RNA: A New Layer of Gene Expression Regulation. ACS Chem. Biol. 2017, 12, 316-325.

(2) Liang, Z.; Riaz, A.; Chachar, S.; Ding, Y.; Du, H.; Gu, X. Epigenetic Modifications of MRNA and DNA in Plants. Mol. Plant 2020, 13, 14-30.

(3) Roundtree, I. A.; Evans, M. E.; Pan, T.; He, C. Dynamic RNA Modifications in Gene Expression Regulation. Cell 2017, 169, 11871200.

(4) Jacob, R.; Zander, S.; Gutschner, T. The Dark Side of the Epitranscriptome: Chemical Modifications in Long Non-Coding RNAs. Int. J. Mol. Sci. 2017, 18, No. 2387.

(5) Yang, Y.; Hsu, P. J.; Chen, Y.-S.; Yang, Y.-G. Dynamic Transcriptomic M6A Decoration: Writers, Erasers, Readers and Functions in RNA Metabolism. Cell Res. 2018, 28, 616-624.

(6) Lence, T.; Paolantoni, C.; Worpenberg, L.; Roignant, J.-Y. Mechanistic Insights into M6A RNA Enzymes. Biochim. Biophys. Acta 2019, 1862, 222-229.

(7) Liu, J.; Yue, Y.; Han, D.; Wang, X.; Fu, Y.; Zhang, L.; Jia, G.; Yu, M.; Lu, Z.; Deng, X.; Dai, Q.; Chen, W.; He, C. A METTL3METTL14 Complex Mediates Mammalian Nuclear RNA N6Adenosine Methylation. Nat. Chem. Biol. 2014, 10, 93-95.

(8) Wang, P.; Doxtader, K. A.; Nam, Y. Structural Basis for Cooperative Function of Mettl3 and Mettl14 Methyltransferases. Mol. Cell 2016, 63, 306-317.

(9) Meyer, K. D.; Jaffrey, S. R. Rethinking M6A Readers, Writers, and Erasers. Annu. Rev. Cell Dev. Biol. 2017, 33, 319-342.

(10) Schöller, E.; Weichmann, F.; Treiber, T.; Ringle, S.; Treiber, N.; Flatley, A.; Feederle, R.; Bruckmann, A.; Meister, G. Interactions, Localization, and Phosphorylation of the M6A Generating METTL3METTL14-WTAP Complex. RNA 2018, 24, 499-512.
(11) Zaccara, S.; Ries, R. J.; Jaffrey, S. R. Reading, Writing and Erasing MRNA Methylation. Nat. Rev. Mol. Cell Biol. 2019, 20, 608624.

(12) Brown, J. A.; Kinzig, C. G.; DeGregorio, S. J.; Steitz, J. A. Methyltransferase-like Protein 16 Binds the 3'-Terminal Triple Helix of MALAT1 Long Noncoding RNA. Proc. Natl. Acad. Sci. U.S.A. 2016, 113, 14013-14018.

(13) Warda, A. S.; Kretschmer, J.; Hackert, P.; Lenz, C.; Urlaub, H.; Höbartner, C.; Sloan, K. E.; Bohnsack, M. T. Human METTL16 Is a N6-Methyladenosine (M6A) Methyltransferase That Targets PreMRNAs and Various Non-Coding RNAs. EMBO Rep. 2017, 18, 2004-2014.

(14) Shima, H.; Matsumoto, M.; Ishigami, Y.; Ebina, M.; Muto, A.; Sato, Y.; Kumagai, S.; Ochiai, K.; Suzuki, T.; Igarashi, K. SAdenosylmethionine Synthesis Is Regulated by Selective N6Adenosine Methylation and MRNA Degradation Involving METTL16 and YTHDC1. Cell Rep. 2017, 21, 3354-3363.

(15) Doxtader, K. A.; Wang, P.; Scarborough, A. M.; Seo, D.; Conrad, N. K.; Nam, Y. Structural Basis for Regulation of METTL16, an S-Adenosylmethionine Homeostasis Factor. Mol. Cell 2018, 71, 1001-1011.

(16) Patil, D. P.; Pickering, B. F.; Jaffrey, S. R. Reading M6A in the Transcriptome: M6A-Binding Proteins. Trends Cell Biol. 2018, 28, 113-127.

(17) Dominissini, D.; Moshitch-Moshkovitz, S.; Schwartz, S.; Salmon-Divon, M.; Ungar, L.; Osenberg, S.; Cesarkas, K.; JacobHirsch, J.; Amariglio, N.; Kupiec, M.; Sorek, R.; Rechavi, G. Topology of the Human and Mouse m 6 A RNA Methylomes Revealed by $\mathrm{m} 6$ A-Seq. Nature 2012, 485, 201-206.

(18) Shi, H.; Wang, X.; Lu, Z.; Zhao, B. S.; Ma, H.; Hsu, P. J.; Liu, C.; He, C. YTHDF3 Facilitates Translation and Decay of N6Methyladenosine-Modified RNA. Cell Res. 2017, 27, 315-328.

(19) Xu, C.; Wang, X.; Liu, K.; Roundtree, I. A.; Tempel, W.; Li, Y.; $\mathrm{Lu}, \mathrm{Z}$.; He, C.; Min, J. Structural Basis for Selective Binding of M6A RNA by the YTHDC1 YTH Domain. Nat. Chem. Biol. 2014, 10, 927-929.

(20) Kretschmer, J.; Rao, H.; Hackert, P.; Sloan, K. E.; Höbartner, C.; Bohnsack, M. T. The M6A Reader Protein YTHDC2 Interacts with the Small Ribosomal Subunit and the $5^{\prime}-3^{\prime}$ Exoribonuclease XRN1. RNA 2018, 24, 1339-1350.

(21) Xu, C.; Liu, K.; Tempel, W.; Demetriades, M.; Aik, W.; Schofield, C. J.; Min, J. Structures of Human ALKBH5 Demethylase Reveal a Unique Binding Mode for Specific Single-Stranded N6Methyladenosine RNA Demethylation. J. Biol. Chem. 2014, 289, 17299-17311.

(22) Zheng, G.; Dahl, J. A.; Niu, Y.; Fedorcsak, P.; Huang, C.-M.; Li, C. J.; Vågbø, C. B.; Shi, Y.; Wang, W.-L.; Song, S.-H.; Lu, Z.; Bosmans, R. P. G.; Dai, Q.; Hao, Y.-J.; Yang, X.; Zhao, W.-M.; Tong, W.-M.; Wang, X.-J.; Bogdan, F.; Furu, K.; Fu, Y.; Jia, G.; Zhao, X.; Liu, J.; Krokan, H. E.; Klungland, A.; Yang, Y.-G.; He, C. ALKBH5 Is a Mammalian RNA Demethylase That Impacts RNA Metabolism and Mouse Fertility. Mol. Cell 2013, 49, 18-29.

(23) Mauer, J.; Sindelar, M.; Despic, V.; Guez, T.; Hawley, B. R.; Vasseur, J.-J.; Rentmeister, A.; Gross, S. S.; Pellizzoni, L.; Debart, F.; Goodarzi, H.; Jaffrey, S. R. FTO Controls Reversible m 6 Am RNA Methylation during SnRNA Biogenesis. Nat. Chem. Biol. 2019, 15, 340-347.

(24) Aik, W.; Scotti, J. S.; Choi, H.; Gong, L.; Demetriades, M.; Schofield, C. J.; McDonough, M. A. Structure of Human RNA N ${ }^{6}$ Methyladenine Demethylase ALKBH5 Provides Insights into Its Mechanisms of Nucleic Acid Recognition and Demethylation. Nucleic Acids Res. 2014, 42, 4741-4754.

(25) Feng, C.; Liu, Y.; Wang, G.; Deng, Z.; Zhang, Q.; Wu, W.; Tong, Y.; Cheng, C.; Chen, Z. Crystal Structures of the Human RNA Demethylase Alkbh5 Reveal Basis for Substrate Recognition. J. Biol. Chem. 2014, 289, 11571-11583.

(26) Deng, X.; Su, R.; Weng, H.; Huang, H.; Li, Z.; Chen, J. RNA N6-Methyladenosine Modification in Cancers: Current Status and Perspectives. Cell Res. 2018, 28, 507-517. 
(27) Zhou, Z.; Lv, J.; Yu, H.; Han, J.; Yang, X.; Feng, D.; Wu, Q.; Yuan, B.; Lu, Q.; Yang, H. Mechanism of RNA Modification N6Methyladenosine in Human Cancer. Mol. Cancer 2020, 19, No. 104.

(28) Gu, C.; Shi, X.; Dai, C.; Shen, F.; Rocco, G.; Chen, J.; Huang, Z.; Chen, C.; He, C.; Huang, T.; Chen, C. RNA M6A Modification in Cancers: Molecular Mechanisms and Potential Clinical Applications. The Innovation 2020, 1, No. 100066.

(29) Thalhammer, A.; Bencokova, Z.; Poole, R.; Loenarz, C.; Adam, J.; O’Flaherty, L.; Schödel, J.; Mole, D.; Giaslakiotis, K.; Schofield, C. J.; Hammond, E. M.; Ratcliffe, P. J.; Pollard, P. J. Human AlkB Homologue 5 Is a Nuclear 2-Oxoglutarate Dependent Oxygenase and a Direct Target of Hypoxia-Inducible Factor $1 \alpha($ HIF- $1 \alpha)$. PLoS One 2011, 6, No. e16210.

(30) Zhang, S.; Zhao, B. S.; Zhou, A.; Lin, K.; Zheng, S.; Lu, Z.; Chen, Y.; Sulman, E. P.; Xie, K.; Bögler, O.; Majumder, S.; He, C.; Huang, S. The M6A Demethylase ALKBH5 Maintains Tumorigenicity of Glioblastoma Stem-Like Cells by Sustaining FOXM1 Expression and Cell Proliferation Program. Cancer Cell 2017, 31, 591-606.

(31) Zhang, C.; Samanta, D.; Lu, H.; Bullen, J. W.; Zhang, H.; Chen, I.; He, X.; Semenza, G. L. Hypoxia Induces the Breast Cancer Stem Cell Phenotype by HIF-Dependent and ALKBH5-Mediated M6ADemethylation of NANOG MRNA. Proc. Natl. Acad. Sci. U.S.A. 2016, 113, E2047-E2056.

(32) Wang, X.; Li, Z.; Kong, B.; Song, C.; Cong, J.; Hou, J.; Wang, S. Reduced M6A MRNA Methylation Is Correlated with the Progression of Human Cervical Cancer. Oncotarget 2017, 8, 98918-98930.

(33) Li, N.; Kang, Y.; Wang, L.; Huff, S.; Tang, R.; Hui, H.; Agrawal, K.; Gonzalez, G. M.; Wang, Y.; Patel, S. P.; Rana, T. M. ALKBH5 Regulates Anti-PD-1 Therapy Response by Modulating Lactate and Suppressive Immune Cell Accumulation in Tumor Microenvironment. Proc. Natl. Acad. Sci. U.S.A. 2020, 117, 20159-20170.

(34) Nagaki, Y.; Motoyama, S.; Yamaguchi, T.; Hoshizaki, M.; Sato, Y.; Sato, T.; Koizumi, Y.; Wakita, A.; Kawakita, Y.; Imai, K.; Nanjo, H.; Watanabe, H.; Imai, Y.; Minamiya, Y.; Kuba, K. M6 A Demethylase ALKBH5 Promotes Proliferation of Esophageal Squamous Cell Carcinoma Associated with Poor Prognosis. Genes Cells 2020, 25, 547-561.

(35) Chen, Y.; Zhao, Y.; Chen, J.; Peng, C.; Zhang, Y.; Tong, R.; Cheng, Q.; Yang, B.; Feng, X.; Lu, Y.; Xie, H.; Zhou, L.; Wu, J.; Zheng, S. ALKBH5 Suppresses Malignancy of Hepatocellular Carcinoma via M6A-Guided Epigenetic Inhibition of LYPD1. Mol. Cancer 2020, 19, No. 123.

(36) Guo, X.; Li, K.; Jiang, W.; Hu, Y.; Xiao, W.; Huang, Y.; Feng, Y.; Pan, Q.; Wan, R. RNA Demethylase ALKBH5 Prevents Pancreatic Cancer Progression by Posttranscriptional Activation of PER1 in an M6A-YTHDF2-Dependent Manner. Mol. Cancer 2020, 19, No. 91.

(37) He, Y.; Hu, H.; Wang, Y.; Yuan, H.; Lu, Z.; Wu, P.; Liu, D.; Tian, L.; Yin, J.; Jiang, K.; Miao, Y. ALKBH5 Inhibits Pancreatic Cancer Motility by Decreasing Long Non-Coding RNA KCNK15AS1 Methylation. Cell. Physiol. Biochem. 2018, 48, 838-846.

(38) Tang, B.; Yang, Y.; Kang, M.; Wang, Y.; Wang, Y.; Bi, Y.; He, S.; Shimamoto, F. M6A Demethylase ALKBH5 Inhibits Pancreatic Cancer Tumorigenesis by Decreasing WIF-1 RNA Methylation and Mediating Wnt Signaling. Mol. Cancer 2020, 19, No. 3.

(39) Yang, P.; Wang, Q.; Liu, A.; Zhu, J.; Feng, J. ALKBH5 Holds Prognostic Values and Inhibits the Metastasis of Colon Cancer. Pathol. Oncol. Res. 2020, 26, 1615-1623.

(40) Chao, Y.; Shang, J.; Ji, W. ALKBH5-M6A-FOXM1 Signaling Axis Promotes Proliferation and Invasion of Lung Adenocarcinoma Cells under Intermittent Hypoxia. Biochem. Biophys. Res. Commun. 2020, 521, 499-506.

(41) Chen, S.; Zhou, L.; Wang, Y. ALKBH5-Mediated M6A Demethylation of LncRNA PVT1 Plays an Oncogenic Role in Osteosarcoma. Cancer Cell. Int. 2020, 20, No. 34.

(42) Jiang, Y.; Wan, Y.; Gong, M.; Zhou, S.; Qiu, J.; Cheng, W. RNA Demethylase ALKBH5 Promotes Ovarian Carcinogenesis in a
Simulated Tumour Microenvironment through Stimulating NF-KB Pathway. J. Cell. Mol. Med. 2020, 24, 6137-6148.

(43) Jin, D.; Guo, J.; Wu, Y.; Yang, L.; Wang, X.; Du, J.; Dai, J.; Chen, W.; Gong, K.; Miao, S.; Li, X.; Sun, H. M6A Demethylase ALKBH5 Inhibits Tumor Growth and Metastasis by Reducing YTHDFs-Mediated YAP Expression and Inhibiting MiR-107/ LATS2-Mediated YAP Activity in NSCLC. Mol. Cancer 2020, 19, No. 40.

(44) Pu, X.; Gu, Z.; Gu, Z. ALKBH5 Regulates IGF1R Expression to Promote the Proliferation and Tumorigenicity of Endometrial Cancer. J. Cancer 2020, 11, 5612-5622.

(45) Zhu, Z.; Qian, Q.; Zhao, X.; Ma, L.; Chen, P. N6Methyladenosine ALKBH5 Promotes Non-Small Cell Lung Cancer Progress by Regulating TIMP3 Stability. Gene 2020, 731, No. 144348.

(46) Zhang, X.; Wang, F.; Wang, Z.; Yang, X.; Yu, H.; Si, S.; Lu, J.; Zhou, Z.; lu, Q.; Wang, Z.; Yang, H. ALKBH5 Promotes the Proliferation of Renal Cell Carcinoma by Regulating AURKB Expression in an M6A-Dependent Manner. Ann. Transl. Med. 2020, $8,646$.

(47) Li, Z.; Weng, H.; Su, R.; Weng, X.; Zuo, Z.; Li, C.; Huang, H.; Nachtergaele, S.; Dong, L.; Hu, C.; Qin, X.; Tang, L.; Wang, Y.; Hong, G.-M.; Huang, H.; Wang, X.; Chen, P.; Gurbuxani, S.; Arnovitz, S.; Li, Y.; Li, S.; Strong, J.; Neilly, M. B.; Larson, R. A.; Jiang, X.; Zhang, P.; Jin, J.; He, C.; Chen, J. FTO Plays an Oncogenic Role in Acute Myeloid Leukemia as a N6-Methyladenosine RNA Demethylase. Cancer Cell 2017, 31, 127-141.

(48) Huang, Y.; Su, R.; Sheng, Y.; Dong, L.; Dong, Z.; Xu, H.; Ni, T.; Zhang, Z. S.; Zhang, T.; Li, C.; Han, L.; Zhu, Z.; Lian, F.; Wei, J.; Deng, Q.; Wang, Y.; Wunderlich, M.; Gao, Z.; Pan, G.; Zhong, D.; Zhou, H.; Zhang, N.; Gan, J.; Jiang, H.; Mulloy, J. C.; Qian, Z.; Chen, J.; Yang, C.-G. Small-Molecule Targeting of Oncogenic FTO Demethylase in Acute Myeloid Leukemia. Cancer Cell 2019, 35, 677-691.

(49) Shen, C.; Sheng, Y.; Zhu, A. C.; Robinson, S.; Jiang, X.; Dong, L.; Chen, H.; Su, R.; Yin, Z.; Li, W.; Deng, X.; Chen, Y.; Hu, Y.-C.; Weng, H.; Huang, H.; Prince, E.; Cogle, C. R.; Sun, M.; Zhang, B.; Chen, C.-W.; Marcucci, G.; He, C.; Qian, Z.; Chen, J. RNA Demethylase ALKBH5 Selectively Promotes Tumorigenesis and Cancer Stem Cell Self-Renewal in Acute Myeloid Leukemia. Cell Stem Cell 2020, 27, 64-80.

(50) Malacrida, A.; Rivara, M.; Di Domizio, A.; Cislaghi, G.; Miloso, M.; Zuliani, V.; Nicolini, G. 3D Proteome-Wide Scale Screening and Activity Evaluation of a New ALKBH5 Inhibitor in U87 Glioblastoma Cell Line. Bioorg. Med. Chem. 2020, 28, No. 115300.

(51) Kowalski-Chauvel, A.; Lacore, M. G.; Arnauduc, F.; Delmas, C.; Toulas, C.; Cohen-Jonathan-Moyal, E.; Seva, C. The M6A RNA Demethylase ALKBH5 Promotes Radioresistance and Invasion Capability of Glioma Stem Cells. Cancers 2021, 13, No. 40.

(52) Shi, Y.; Cui, Q. M6A MRNA Modification in Cancer Treatment, 2018.

(53) Su, R.; Dong, L.; Li, Y.; Han, L.; Gao, M.; Wunderlich, M.; Deng, X.; Li, H.; Gao, L.; Li, C.; Robison, S.; Tan, B.; Qing, Y.; Qin, X.; Prince, E.; Xie, J.; Qin, H.; Huang, Y.; Li, W.; Chen, J.; et al. Effective Novel Fto Inhibitors Show Potent Anti-Cancer Efficacy and Suppress Drug Resistance. Blood 2019, 134, 233.

(54) Wang, J.; Li, Y.; Wang, P.; Han, G.; Zhang, T.; Chang, J.; Yin, R.; Shan, Y.; Wen, J.; Xie, X.; Feng, M.; Wang, Q.; Hu, J.; Cheng, Y.; Zhang, T.; Li, Y.; Gao, Z.; Guo, C.; Wang, J.; Liang, J.; Cui, M.; Gao, K.; Chai, J.; Liu, W.; Cheng, H.; Li, L.; Zhou, F.; Liu, L.; Luo, Y.; Li, S.; Zhang, H. Leukemogenic Chromatin Alterations Promote AML Leukemia Stem Cells via a KDM4C-ALKBH5-AXL Signaling Axis. Cell Stem Cell 2020, 27, 81-97.

(55) Han, S. H.; Choe, J. Diverse Molecular Functions of m 6 A MRNA Modification in Cancer. Exp. Mol. Med. 2020, 52, 738-749.

(56) Madhavi Sastry, G.; Adzhigirey, M.; Day, T.; Annabhimoju, R.; Sherman, W. Protein and Ligand Preparation: Parameters, Protocols, and Influence on Virtual Screening Enrichments. J. Comput.-Aided Mol. Des. 2013, 27, 221-234. 
(57) Morris, G. M.; Huey, R.; Lindstrom, W.; Sanner, M. F.; Belew, R. K.; Goodsell, D. S.; Olson, A. J. AutoDock4 and AutoDockTools4: Automated Docking with Selective Receptor Flexibility. J. Comput. Chem. 2009, 30, 2785-2791.

(58) Stephens, P. J.; Devlin, F. J.; Chabalowski, C. F.; Frisch, M. J. $\mathrm{Ab}$ Initio Calculation of Vibrational Absorption and Circular Dichroism Spectra Using Density Functional Force Fields. J. Phys. Chem. A 1994, 98, 11623-11627.

(59) Bowers, K. J.; Chow, D. E.; Xu, H.; Dror, R. O.; Eastwood, M. P.; Gregersen, B. A.; Klepeis, J. L.; Kolossvary, I.; Moraes, M. A.; Sacerdoti, F. D.; Salmon, J. K.; Shan, Y.; Shaw, D. E. In Scalable Algorithms for Molecular Dynamics Simulations on Commodity Clusters, Proceedings of the 2006 ACM/IEEE Conference on Supercomputing, SC'06, 2006; p 43.

(60) Banks, J. L.; Beard, H. S.; Cao, Y.; Cho, A. E.; Damm, W.; Farid, R.; Felts, A. K.; Halgren, T. A.; Mainz, D. T.; Maple, J. R.; Murphy, R.; Philipp, D. M.; Repasky, M. P.; Zhang, L. Y.; Berne, B. J.; Friesner, R. A.; Gallicchio, E.; Levy, R. M. Integrated Modeling Program, Applied Chemical Theory (IMPACT). J. Comput. Chem. 2005, 26, 1752-1780.

(61) Toukmaji, A. Y.; Board, J. A. Ewald Summation Techniques in Perspective: A Survey. Comput. Phys. Commun. 1996, 95, 73-92.

(62) Zielkiewicz, J. Structural Properties of Water: Comparison of the SPC, SPCE, TIP4P, and TIP5P Models of Water. J. Chem. Phys. 2005, 123, No. 104501.

(63) Pai, M. Y.; Lomenick, B.; Hwang, H.; Schiestl, R.; McBride, W.; Loo, J. A.; Huang, J. Drug Affinity Responsive Target Stability (DARTS) for Small Molecule Target Identification. Methods Mol. Biol. 2015, 1263, 287-298.

(64) Huang, Y.; Yan, J.; Li, Q.; Li, J.; Gong, S.; Zhou, H.; Gan, J.; Jiang, H.; Jia, G.-F.; Luo, C.; Yang, C.-G. Meclofenamic Acid Selectively Inhibits FTO Demethylation of M6A over ALKBH5. Nucleic Acids Res. 2015, 43, 373-384. 